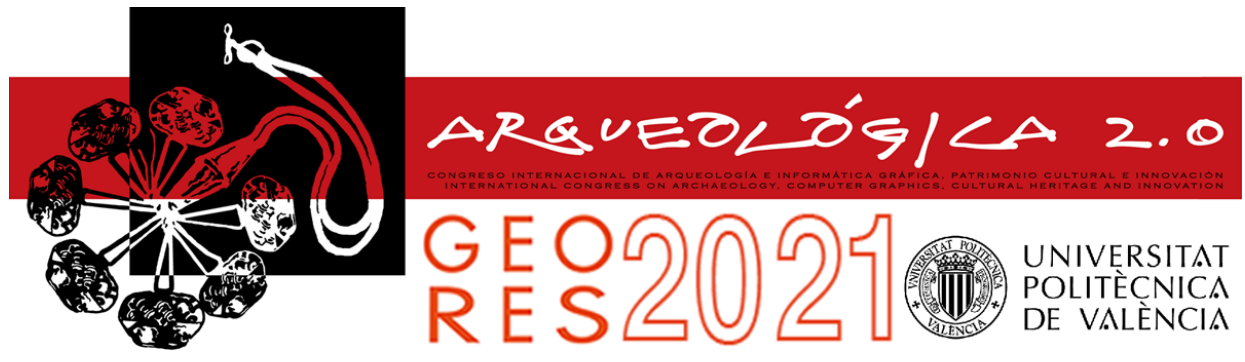

\title{
AN INFORMATIVE TOOL FOR THE PRESERVATION OF THE WOODEN ENCIRCLING TIE ROD OF THE DOME OF SANTA MARIA DEL FIORE, IN FLORENCE
}

\author{
Sofia Celli*, Federica Ottoni \\ Department of Engineering and Architecture, Università di Parma, Viale Parco Area delle Scienze 181/A, 43124 Parma, Italy. \\ sofia.celli@unipr.it; federica.ottoni@unipr.it
}

\begin{abstract}
:
Proceeding under the assumption that restorers need to become more involved in the definition of the most advanced management tools for historic buildings, this paper aims to offer a contribution to the "informative" feature of the H-BIM methodology. Indeed, over the past few years, the issues addressed by scholars mostly concerned surveying and modelling techniques, whereas the organization of external data within the virtual model has rarely been considered. The necessity of defining a new operative tool for the maintenance of the wooden chain encircling the dome of Santa Maria del Fiore represented an occasion to develop an informative model that attempts to confer centrality to the knowledge process as a whole. Attention was thus focused on the articulation of the informative apparatus to be associated to the 3D model, as well as to its practical implications in terms of conservation.
\end{abstract}

Keywords: informative model, planned preventive conservation, Santa Maria del Fiore's dome, wooden hooping tie rod

\section{Introduction}

The continuous enhancement of surveying and modelling technologies has been the focal point of the research concerning the relationship between geomatics and restoration over the past few years (Brumana et al., 2018; Banfi, Fai, \& Brumana, 2017; Castagnetti et al., 2017; Tommasi, Achille, \& Fassi 2016). However, in order for the H-BIM methodology to further improve its efficacy as a tool to support conservation activities, it seems opportune to start focusing also on the informative apparatus to be associated with the 3D model (Bruno \& Roncella, 2019). In particular, it might be useful to identify which data are the most useful in terms of conservation and how they could most effectively be organized to help planning and performing inspections and maintenance.

Clearly, given the intrinsic specificity of historical heritage, it will not be possible to develop a fixed system to be slavishly applied to any case study. The definition of a few guidelines might however help to structure operative and conservation-driven information models.

The wooden hooping tie-rod encircling the dome of Santa Maria del Fiore, hence became the occasion to develop an informative model which, focusing on data organization, aims at validly supporting all those conservation activities that are fundamental to ensure the preservation of this famous monumental complex.

\section{The wooden hooping tie rod of Brunelleschi's dome}

As well known, when the construction of the Florentine cathedral's dome started in 1420, masons followed the detailed instructions provided by the work program outlined by Filippo Brunelleschi and Lorenzo Ghiberti. Among other directives, the two architects pointed out the necessity of encircling the dome with a complex system of hoops comprising several orders of stone, wood and iron tie rods (Ottoni \& Blasi, 2015). Although not expressly declared, the aim of such expedients was to absorb the physiological horizontal thrust of the masonry dome that, at the time, had already been empirically acknowledged as the main cause of collapse of this type of structures (Como, Iori, \& Ottoni, 2019; Ottoni \& Blasi, 2016). While the four stone chains - partly visible - have been widely analyzed and the actual presence of iron hoops is yet to be verified (Corazzi \& Conti, 2011), little attention has been paid to the wooden ring located at the base of the dome (Figs. 1-3).

Composed of twenty-four chestnut beams connected by means of metallic joints, the hoop - installed between 1423 and 1424 - was supposed to be the first of four, but it ended up being the only one. Indeed, the amendments made to the original construction program in 1426 resulted in the dismissal of any further wooden tie (Mainstone, 1970), which would have however proven

‘Corresponding Author: Sofia Celli, sofia.celli@unipr.it 
somehow superfluous, considering that the maximum stress is recorded in the proximity of the vault's springer.

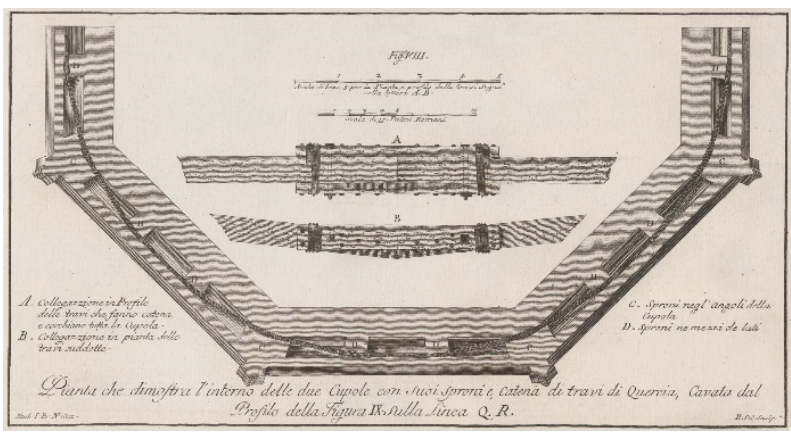

Figure 1: The wooden tie as represented by Giovan Battista Nelli at the end of the XVII century (Sgrilli, 1733 - tav. VII).

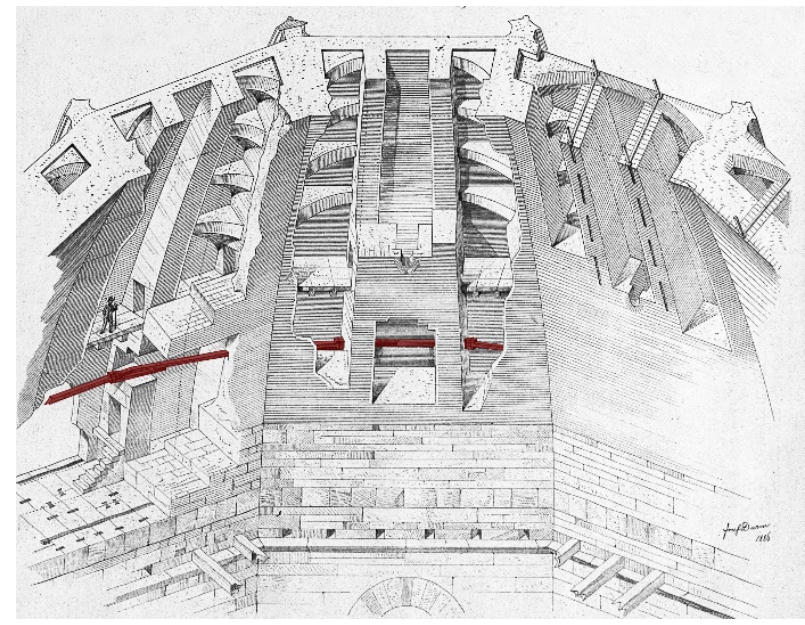

Figure 2: The structural arrangement of Santa Maria del Fiore's dome in Josef Durm representation. Marked in red the wooden hooping tie rod (Durm, 1887).

Ever since its construction, the wooden chain surrounding Santa Maria del Fiore's dome has thus been the subject of an intense debate due both to the fact that only one out of the four foreseen hoops was actually built and to the material choice (wood), which does not seem particularly fitting for an element designed to last in time. Responsible for causing significant disagreements between Brunelleschi and Ghiberti as soon as the time of its installation (Manetti, 1976), this device has kept arousing the interest of scholars who, over the centuries, have provided the most diverse interpretations regarding its function and its contribution to the Dome in terms of stability. As a matter of fact, although many have resolutely recognized the wooden structure to be an element designed to counteract the horizontal thrusts resulting from hoop tension (Fontana, 1696; Saalman, 1980; Tampone, 1996; Blasi, Ottoni, Coïsson, \& Tedeschi, 2017), many others claim that it was a device built exclusively to gain greater control of the building site or even useless (Prager \& Scaglia, 1970; Sanpaolesi, 1977; Rossi, 1982). The shifting of opinions on this regard reflected on the preservation of this artifact which has alternatively undergone periods of constant care and periods of substantial neglect. For instance, in the 1900s, the persuasion that the static contribution of the wood ring to the global equilibrium of the dome was close to none (Sanpaolesi, 1977) led to minimal repairs to the device. Luckily enough the punctual maintenance of all the surrounding elements - with particular reference to the external cap and its tile covering, which forbade water infiltration - has guaranteed the conservation of the wooden tie. Although today renewed attention is being paid to this ancient encircling device, its peculiar nature calls for the reinstatement of those good practices that ensured its permanence throughout the centuries.

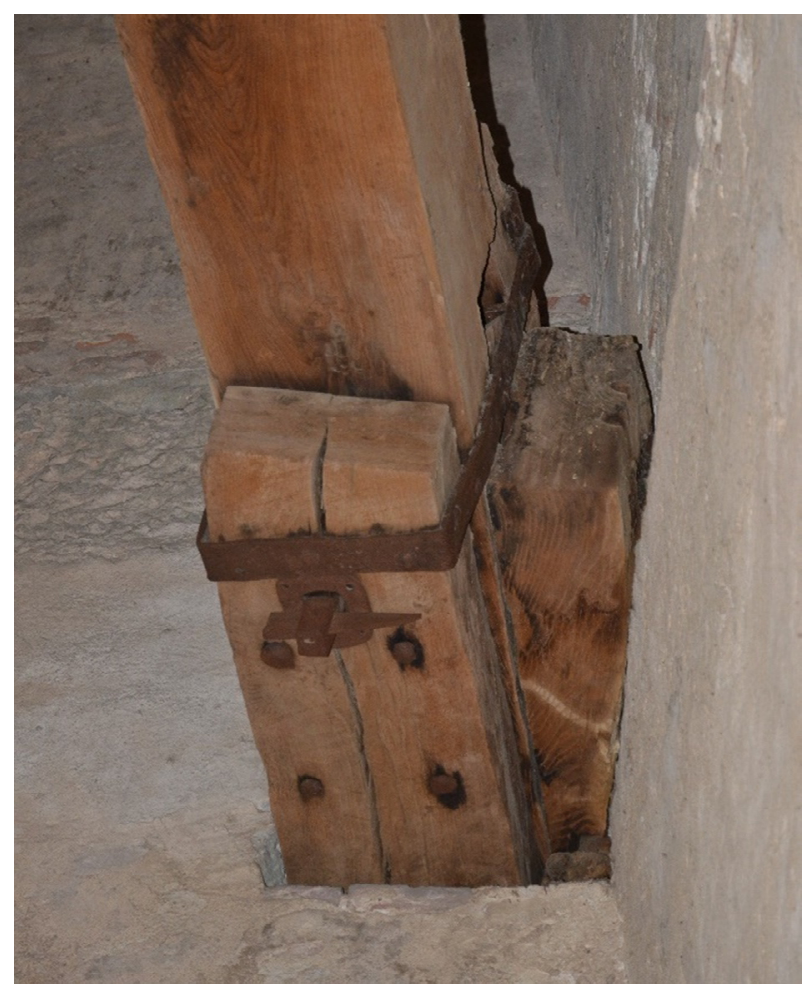

Figure 3: One of the metallic joints connecting the beams of the chestnut chain (photograph taken by the authors).

The need to develop a brand-new preservation strategy for Santa Maria del Fiore's chestnut chain made it the ideal case study to attempt to define a modus operandi that could be diffusely applied to the built heritage. Thus, starting from the canonical data retrieval, the present research explores the potential of an informative model aimed both at supporting the planning and completion of conservation activities and at boosting the knowledge process.

\section{The archival research}

Despite the great amount of writings and publications that, especially since the late nineteenth century, has led to clarify many aspects of the constructive system of Brunelleschi's dome, so far only few scholars have focused their attention on the wooden hooping tie (Blasi, Ottoni, Coïsson, \& Tedeschi, 2017; Ottoni \& Blasi, 2016; CNR-IVALSA, 2014; Tampone, 1996; Ricci, 1989). None of them has however conducted a systematic study aimed at better understanding its construction process, pinpointing the events and maintenance works that shaped it over time, making it what we get to see today.

As noted by Gennaro Tampone: «there is quite a lot of work yet to be done in order to obtain a complete and meticulous survey of the whole chain and its joints, to distinguish the authentic parts from the ones that were added later on, and, above all, to define with greater 
discernment the role, functioning and efficacy of the device in terms of both its individual components and as a whole. It is also important to analyze the state of repair of wooden elements, as well as the efficiency of their connections». The need for an accurate study that, based on reliable data, could help dispel at least some of the centuries-old doubts concerning the wooden chain, appears therefore clear.

To this purpose, also taking into account the relevance of historical investigation within the conservation process (De Fusco, 1980), the first activity that was carried out was a thorough bibliographic and archival research. After the analysis of published materials (Guasti, 1857; Haines, 2015) - which helped to isolate some significant dates, mostly related to catastrophic events such as earthquakes and lightening - the study turned to the massive documentation stored at the historical archive of the Opera of Santa Maria del Fiore. While books and journals have been extremely useful to piece together a sort of anthology of opinions on what the original function of the chain was supposed to be, historic papers proved essential to investigate its construction and maintenance history. Pieces of information emerged from archival documentation - integrated with geometrical data retrieved from the most recent laser scanner survey (conducted by Studio Scaletti e Studio Comes in 2018 upon request of the Opera di Santa Maria del Fiore) allowed to spatially locate the repairs described by the ancient craftsmen (mostly blacksmiths and woodworkers), and hence to set a date to most of the elements composing the hoop tie rod.

\section{Towards a planned preventive conservation}

Citing Bellini, we can say that: «if the primary scope is conservation, the first aim of ad hoc historical investigation is the examination of the circumstances that materially produced and modified the building" (Bellini, 1980). Knowledge acquired through historical investigation ought to find operative implications in restoration activities, as stated by the so called "planned conservation" (Della Torre, 2003). Indeed, such strategy proposes a conceptual shift from major interventions to constant and preventive care, conferring great importance to inspections and minor maintenance activities. The reiteration of these actions keeps generating new information that will help calibrate further steps, thus feeding into a virtuous cycle of knowledge. This is especially relevant in the field of cultural heritage since there are no certain predictions concerning the lifespan of the individual elements composing each building. Conservation activities are hence planned on the basis of empirical observations and recurring monitoring. In this respect, historical data are a precious resource, as they increase the overall acquaintance with the object while possibly highlighting causal relationships that can significantly improve the conservation activities planning. (Cecchi \& Gasparoli, 2010).

However, in order to satisfactorily fulfil this purpose, it is necessary to address the still open issue of data managing, which could be summarized as the identification of the most fitting procedure to critically select, organize and file information to make it easily accessible support for the preservation process. The proposed solution, tested on the wooden hooping tie of
Santa Maria del Fiore's dome, is an informative model that aims at making data available to all the actors involved in the conservation process, facilitating the planning and completion of different activities, but also fostering better communication between the various professional figures involved.

Although experimentally implemented only for the chestnut chain, the tool should be further developed to gather information concerning the whole dome, in order to supply the technicians with a unified and integrated model which would simplify the global management of the entire monumental complex.

\section{The 3D model}

The first step in the definition of the informative tool of Santa Maria del Fiore in Florence, has been the setting up of a simplified 3D model, based on consistent geometrical regularization (Fig. 4).

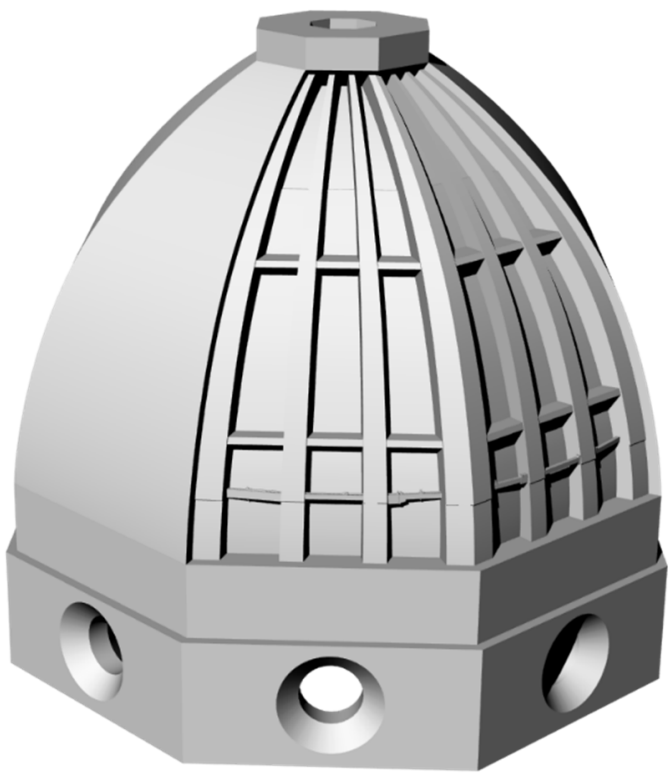

Figure 4: The 3D model of the dome of Santa Maria del Fiore inclusive of all its main construction elements.

In fact, the difficulties connected to the modelling of complex shapes are widely acknowledged and constitutes one of the main challenges in the application of BIM methodology to historic heritage (Brumana et al., 2018; Banfi, Fai, \& Brumana, 2017; Tommasi, Achille, \& Fassi 2016).

Since the idea of a Historic or Heritage BIM came to life (Murphy, McGovern, \& Pavia 2009), studies have mainly focused on geomatics, working on improving the existing survey technologies as well as the following data processing and modelling (Brumana et al, 2020). Indeed, one of the most peculiar features of historic buildings is their irregularity. Traditional craftsmanship in manufacturing, traumatic events, transformations in use, as well as the mere passage of time, resulted in stratifications, deformations, disarray, unique marks of the inevitable changeableness of existence (Bellini, 1996). Such specificities are however difficult to manage in terms of both survey and modelling, mostly because of the need to find the right balance between geometric 
accuracy, input resources (time and money), and outcome manageability (file size).

Moreover, most BIM software uses parametric modelling, which is extremely useful when operating on new buildings, but rather inadequate for cultural heritage. A possible way to overcome this problem is, of course, to turn to $3 \mathrm{D}$ modelling software. Despite this solution guarantees more freedom in the development of complex shapes, interoperability issues might arise when importing the model into the BIM software with the risk of losing part of the data or properties. This topic, partly dealt with in recent years, should be further explored as a pivotal point. In fact, "research on the so-called "historic BIM" should avoid the risk of being limited to the representation of historic architecture. Instead, it should exploit the potentials of electronic interoperable tools for the regularization of conservation phases» (Della Torre, 2020).

Starting from these assumptions, and given the main objective of the research, a simplified model was considered suitable for the task. Indeed, the level of detail - as well as the level of information - should be defined according to the final purpose. In the specific case, a conceptual model appeared to be the best solution in order to provide quick access to a large amount of information required to support conservation activities. Within the case study, metric accuracy was hence moved to the background in favour of other aspects pointing towards an improved preservation strategy. The soundness of this approach has been pointed out by several scholars (Ottoni, Zerbi, \& Freddi, 2017) who underlined how higher accuracy is not necessarily the answer to the problem, whereas geometric precision should always be calibrated considering the target.

The 3D model of the dome of Santa Maria del Fiore has hence been shaped based on the photogrammetric survey conducted by F.O.A.R.T. (Dalla Negra, 2004), which was schematized in consideration of the study of the original proportions of the dome as emerged from the 1420 construction program. As for the wood ring, geometrical information was taken from the recent laser scanner survey of 2018.

The model comprises all the main construction elements of the dome, such as the two caps - external and internal, both divided into eight webs -, the 24 ribs, the walkways delimiting the three levels of the structure, and finally the wooden chain. The latter is further subdivided into beams and joints, so that it will be possible to associate information to both wooden and metallic elements.

As a matter of fact, even though the geometrical accuracy is rather low, each object is immediately recognizable, guaranteeing an intuitive retrieval of the georeferenced data. However, in order not to lose precious data, the informative tool has been arranged so that it will be possible to associate further and more precise geometrical information to the model, such as detailed 2D/3D representations or even the original point clouds. The possibility to withdraw firsthand data will allow both to verify the reliability of possible previous studies and to carry out further analysis that might require higher geometrical definition.

\section{The informative tool}

As previously mentioned, although the 3D model represents the whole dome, the informative structure has so far only been implemented with regard to the wooden tie-rod, the main concern of the presented research (Fig. 5).

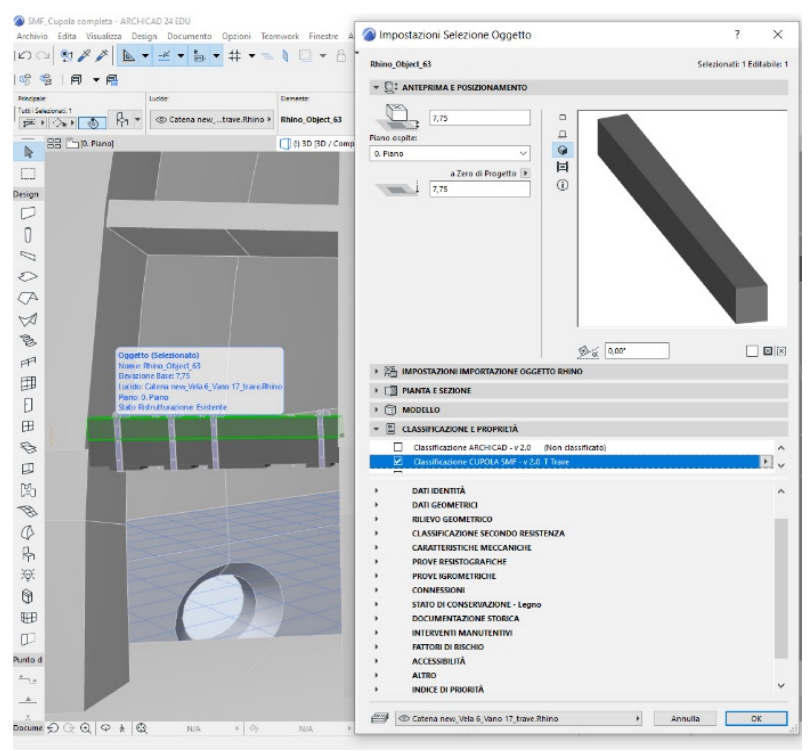

Figure 5: A screenshot of the informative model.

Before actually start organizing data, it appeared necessary to clearly state the purposes of the information model, in order to be able to develop it accordingly. In particular, four focal points were identified:

- Create a repository to store available information concerning the dome's wooden hoop (and possibly the global structure of the dome) in an orderly system;

- Supply the technical office of the Opera of Santa Maria del Fiore with an operational tool suited to simplify the conservation and general management process;

- Foster coherent interventions by favouring a more efficient dialogue among the actors involved throughout the conservation process;

- Ensure large-scale accessibility and userfriendliness of the proposed instrument.

Once set the objectives, the informative tool was structured as briefly described in the following paragraphs.

\subsection{An operational support}

The most basic function of the model is that of collecting heterogeneous data and sort them in an intelligible way, in order to be easily retrievable when needed. Information is gathered together depending on their nature to create thematic groups, such as identity data, geometric data, mechanical properties, and so forth. The idea is that of offering the most comprehensive description of each element, providing restorers with the knowledge that should lead any intervention on cultural heritage. However, as aforementioned, the ambition is higher, as 
the proposed tool wishes to become operational support to preservation activities.

Working towards improved management of the asset, sets of information have been outlined following the guidance offered by the Italian standard UNI 11257:2007, which reports the main criteria for the drafting of a conservation plan (both for existing and underconstruction buildings).

Attention was especially focused on more efficient planning of inspective and maintenance activities. In this regard, looking beyond the mere description of the single analyzed objects, the aim is to provide information to help define a numerical index expressing an overall and concise assessment of their current condition. Such value will thus determine the priority of intervention, with positive repercussions on the scheduling of conservation interventions.

The proposal is that of a priority index that takes into account three main features, namely: historical and architectural value, damage conditions, and risk conditions (Fig. 6).

\begin{tabular}{|c|c|c|}
\hline 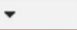 & INDICE DI PRIORITÀ & \\
\hline 5 & Indice di priorità & 13 \\
\hline 5 & VALORE STORICO-ARCHITETTONICO & 4 \\
\hline 河 & Datazione & 5 \\
\hline 河 & Qualità di lavorazione & 3 \\
\hline 河 & CONDIZIONI DI DANNO & 5 \\
\hline 河 & Degrado materico & 5 \\
\hline 河 & Perdita di efficacia & 5 \\
\hline 河 & CONDIZIONI DI RISCHIO & 4 \\
\hline 宫 & Periodo di ispezione & 5 \\
\hline 四 & Criticità & 2 \\
\hline
\end{tabular}

Figure 6: The priority index information set.

Each one of the three entries will be assigned a number from 0 to 5 , being 0 the highest score (excellent) and 5 the lowest one (extremely bad). Such a number will represent the average of the scores (from 0 to 5 ) appointed to the respective subitems. In particular, the historical-architectural value will result from dating and quality of workmanship; damage condition from the state of repair and loss of efficacy; and risk condition from inspection period and criticalities. The priority index will be obtained by adding up the three scores, and it will hence range from 0 to 15 , where 15 will represent maximum urgency and 0 minimum urgency. Each score will descend from throughout examinations of the collected data, which will be displayed in the corresponding sets of information (Ottoni, Coïsson, \& Brignoli, 2014).

\subsubsection{Historical and architectural value}

The historical-architectural value is determined by the dating of the analyzed element and its quality of workmanship. As for the former, 5 points will be assigned in case the object in question is original (thus dating back to the $15^{\text {th }}$ century), whereas 0 points will be given to the most recent additions (from the $21^{\text {st }}$ century onwards).

On the other hand, the latter is a quality assessment, and should be expressed in relation to the technical knowledge of the period of construction. Five points will indicate a very fine and technically advanced work, while zero points will stand for extremely poor technique and realization.

\subsubsection{Damage conditions}

\subsubsection{State of repair}

An essential evaluation to be done in order to assess the conditions of the element in question regards the state of repair (Fig. 7). Indeed, if unresolved, material decay may lead to material loss causing irreversible damages in terms of authenticity and value.

In order to homogenize terminology and facilitate a univocal understanding of the information, items included in this set of data were named following existing standards. For instance, when considering wooden beams, decay pathologies were deduced from the Italian standard UNI 11130:2004.

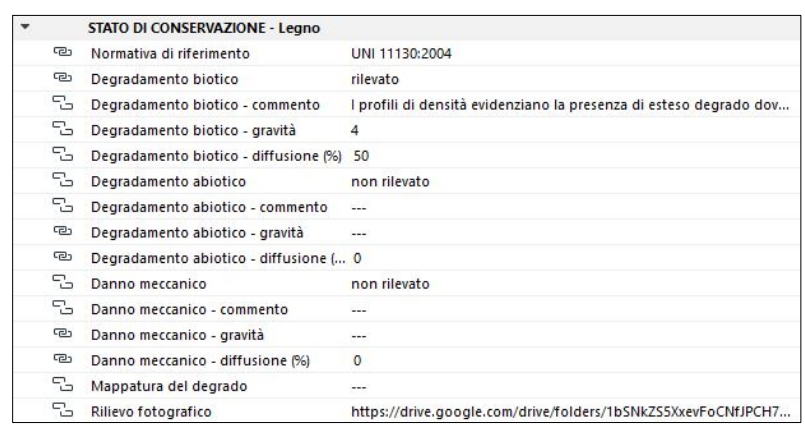

Figure 7: The set of information to describe the state of repair of wooden elements.

Each identified pathology is described through four entries, derived from the 2003 guidelines for the drafting of maintenance plans (Della Torre, 2003). The first one simply indicates whether the specific kind of decay has been detected or not; the second one textually describes the ongoing phenomenon; the third one offers an evaluation (1 to 5 ) concerning the seriousness of the situation; the fourth one quantifies the extent of the damage in percentual.

Complementary data and descriptive files (such as photographs or $2 \mathrm{D}$ thematic maps) can also be added as external hyperlinks.

\subsubsection{Loss of efficacy}

Another aspect to carefully consider when defining intervention priority is mechanical properties. This is particularly true since the wooden chain plays an (although minimal) structural role. It is hence important to establish whether the device is still able to fulfil its task or needs strengthening.

Information can be sourced alternatively from regulations providing average values (in the specific case, for wooden beams the reference was to UNI 11035-2), from standardized visual inspection procedures (as described in UNI 11119:2004 for wooden elements) or from on-site instrumental tests.

Although the first option could supply a plausible suggestion, in order to correctly evaluate residual properties - and consequently set a representative priority index - the second and third options are preferable, as they somehow measure the object itself. 
A precompiled set of information has also been arranged for wooden beams according to UNI 11119:2004 to guide operators during visual inspection procedures.

A last appraisal should regard the efficacy of the strengthening interventions conducted on the wooden ring throughout the centuries. In fact, as emerged from historical investigation, several repairs were done on the wooden chain, often improving the joints' efficiency and installing additional metallic tie-rods.

Such evaluations are complementary to those concerning mechanical properties, as both these aspects condition the structural performance of the encircling device.

\subsubsection{Risk conditions}

\subsubsection{Inspection period}

The date of the latest inspection or intervention should also be considered, as it reflects on the reliability of all the other data. Clearly, if the last inspection dates many years back, information collected on that occasion might not be truthful anymore, as the situation has probably evolved and possibly worsened. It is therefore obvious that the longer time has passed since the latest inspection, the higher the priority to schedule a new one.

In this regard, the informative model presents a set of information designed to record the chronology of interventions (date and nature). The table includes an entry where to signal the possible presence of monitoring systems (either instrumental or visual) and a further field for notes.

\subsubsection{Criticalities}

In addition to the information related to previous inspections, a set of data has been arranged in order to assess risks, highlighting the main criticalities detected and thus the major aspects to keep under control. The dedicated table will include insights concerning interactions with other elements and possible solutions to address risks and better manage the global situation.

Useful suggestions for future conservation activities are also offered by the accessibility section, which provides details about the ease of inspection of the specific object, expressing evaluations in terms of lighting, visibility and possibility to physically reach the element in question. In both cases, it is possible to add further textual advice (e.g. equipment needed, preliminary activities to carry out before the inspections etc.).

\subsection{Sharing of information}

The advantages of the informative tool also concern the interaction between the actors involved in the conservation process. Indeed, while the need for an integrated approach within the field of restoration is by now widely acknowledged, it is still difficult to orchestrate the numerous activities carried out by different professionals. In this regard, the opportunity to provide each one of them with the same all-encompassing model, will reduce materials exchange, resulting in an increased coherence among the proposed designs and solutions. Moreover, the fact that every actor will have access to information in its totality, should encourage and facilitate dialogue, keeping everyone up to speed on the most recent events.

Finally, the possibility of accessing the informative tool by means of an application available for mobile devices will have positive effects on the quality of all conservation activities. Operators will be able to consult the database right on the spot, making comparisons, dispelling possible doubts and acquiring an overall deeper knowledge of the element in question.

\section{Conclusions}

The proposed tool - which currently only gathers data related to the wooden chain - could be implemented by inserting information concerning the whole dome structure, allowing to correlate the different construction elements composing the dome. This would result in further improvements in the overall conservation process of the asset, with positive implication in terms of resources management.

As noted, the informative model primarily represents an instrument to support conservation activities. At the same time, however, it outlines a possible methodology to be exported within the cultural heritage environment, with the hope that, in the next future, restorers will become more involved in the articulation of the new powerful technologies at their disposal.

\section{Acknowledgements}

The presented research has been made possible thanks to the Opera del Duomo di Firenze which promoted the most recent studies concerning the wooden chain of Santa Maria del Fiore. A sincere thank also goes to the archivists of the Opera's historical archive who guided our steps through the archive collection, as well as to Studio Scaletti and Studio Comes (Prof. Carlo Blasi) who provided the latest geometric survey of the chain in question.

\section{References}

Banfi, F., Fai, S., \& Brumana, R. (2017). BIM automation: advanced modeling generative process for complex structures. ISPRS Annals of Photogrammetry, Remote Sensing and Spatial Information Sciences, IV-2/W2, 9-16. https://doi.org/10.5194/isprs-annals-IV-2-W2-9-2017

Bellini, A. (1980). Ricchi apparati e povere idee, Restauro, 51.

Bellini, A. (1996). A proposito di alcuni equivoci sulla conservazione. TeMA, 1, 2-3.

Blasi, C., Ottoni, F., Coïsson, E., \& Tedeschi, C. (2017). Battistero di San Giovanni in Firenze. Note su dissesti, lesioni e catene. In F. Gurrieri (ed.), II Battistero di San Giovanni. Conoscenza, diagnostica, conservazione (pp. 119-133). Firenze, Italy: Mandragora. 
Brumana, R., Della Torre, S., Previtali, M., Barazzetti, L., Cantini, L., Oreni, D., \& Banfi, F. (2018). Generative HBIMmodeling to embody complexity. Surveying, preservation, site intervention. The Basilica di Collemaggio (L'Aquila), Applied Geomatics 10(4), 545-567. https://doi.org/10.1007/s12518-018-0233-3

Brumana, R., Oreni, D., Barazzetti, L., Cuca, B., Previtali, M., \& Banfi, F. (2020). Survey and Scan to BIM Model for the Knowledge of Built Heritage and the Management of Conservation Activities. In B. Daniotti, M. Gianinetto, S. Della Torre (Eds.), Digital Transformation of the Design, Construction and Management Process of the Built Environment (pp. 391-400). https://doi.org/10.1007/978-3-030-33570-0_35

Bruno, N. (2018). From survey to analysis for Cultural Heritage management: a new proposal for database design in BIM, Doctoral Thesis (Supervisor: R. Roncella), Scuola di Dottorato in Ingegneria Civile e Architettura, Università di Parma.

Bruno, N., \& Roncella, R. (2019). HBIM for conservation: a new proposal for information modeling, Remote Sensing, 11(15), 1751. https://doi.org/10.3390/rs11151751

Castagnetti, C., Dubbini, M., Ricci, P.C., Rivola, R., Giannini, M., \& Capra, A. (2017). Critical issues and key points from the survey to the creation of the historical building information model: the case of Santo Stefano Basilica. International Archives of Photogrammetry, Remote Sensing and Spatial Information Sciences, XLII-5/W1, 467-474. https://doi.org/10.5194/isprs-archives-XLII-5-W1-467-2017

Cecchi, R., \& Gasparoli, P. (2010). Prevenzione e manutenzione per i beni culturali edificati. Procedimenti scientifici per lo sviluppo delle attività ispettive, Cesena, Italy: Alinea Editrice.

CNR-IVALSA. (2014). Relazione preliminare sullo stato di conservazione e tensionale di alcuni elementi lignei della cupola di Santa Maria del Fiore in Firenze.

Como, M., Iori, I., \& Ottoni, F. (2019). Scientia abscondita. Arte e scienza del costruire nelle architetture del passato, Venice, Italy: Marsilio.

Corazzi, R., \& Conti, G. (2011). I/ segreto della cupola del Brunelleschi, Firenze, Italy: Pontecorboli.

Dalla Negra, F. (2004). La Cupola di Santa Maria del Fiore. Il rilievo fotogrammetrico. Livorno, Italy: Sillabe.

De Fusco, R. (1980). II restauro architettonico: ricchi apparati e povere idee. Op. cit., 49.

Della Torre, S. (2003). La conservazione programmata del patrimonio storico architettonico. Milan, Italy: Guerrini e Associati.

Della Torre, S. (2020). Italian perspective on the planned preventive conservation. Frontiers of Architectural Research. https://doi.org/10.1016/j.foar.2020.07.008

Durm, J. (1887). Die domkuppel in Florenz und die kuppel der Peterskirche in Rom, Berlin, Germany: Verlag Von Ernst \& Korn.

Fontana, F. (1696). Relazione dell'ultima visita del Cav. Francesco Fontana. Archivio dell'Opera di Santa Maria del Fiore (AOSMF) III.1.19, fasc. 305.

Guasti, C. (1857). La Cupola di Santa Maria del Fiore illustrata con i documenti dell'Archivio dell'Opera secolare, Florence, Italy: Barbèra, Bianchi e Comp.

Haines, M. (2015). Gli Anni della Cupola. Archivio digitale delle fonti dell'Opera di Santa Maria del Fiore, 1417-1436, Opera di Santa Maria del Fiore. Retrieved March 15, 2021, from https://duomo.mpiwg-berlin.mpg.de

Mainstone, R.J. (1969). Brunelleschi's Dome of Santa Maria del Fiore and some related structures. Transaction of the Newcomen Society, 42(1), 107-126. https://doi.org/10.1179/tns.1969.006

Manetti, A. (1976). Vita di Filippo Brunelleschi, Milan, Italy: II Polifilo.

Murphy, M., McGovern, E., \& Pavia, S. (2009). Historic Building Information Modelling (HBIM). Structural Survey, 27(4), 311-327. https://doi.org/10.1108/02630800910985108

Nelli, C. (1753). Discorsi di Architettura del senatore Giovan Batista Nelli. Florence, Italy: Per gli Eredi Paperini.

Ottoni, F., Coïsson, E., \& Brignoli, A. (2014). Edifici storici in zona sismica: per una programmazione degli interventi, tra economia e sicurezza. In Safe Monuments 2014. Tra conservazione e sicurezza di edifici monumentali e del costruito storico, Florence, Italy: Edizioni Collegio degli Ingegneri della Toscana.

Ottoni, F., \& Blasi, C. (2015). Results of 60 years-monitoring system on Santa Maria del Fiore dome, in Florence. International Journal of Architectural Heritage, 9(1), 7-24. http://dx.doi.org/10.1080/15583058.2013.815291

Ottoni, F., \& Blasi, C. (2016). Hooping as an Ancient Remedy for Conservation of Large Masonry Domes. International Journal of Architectural Heritage, 10(2-3), 164-181. https://doi.org/10.1080/15583058.2015.1113335

Ottoni, F., Zerbi, A., \& Freddi, F. (2017). Dalla realtà al modello, e ritorno. Riflessioni sul rilievo e astrazione per la conservazione del patrimonio culturale, ANANKE speciale GEORES 2017, 70-75.

Prager, F. D., \& Scaglia, G. (1970). Brunelleschi. Studies of his technology and inventions. New York, USA: Dover 
Publications Inc.

Ricci, M. (1989). La catena de' castagni della cupola di S. Maria del Fiore. In G. Tampone (Ed.), Legno e restauro. Ricerche e restauri su architetture e manufatti lignei (pp.89-93).

Rossi, P. A. (1982). Le cupole del Brunelleschi. Bologna, Italy: Edizioni Calderini.

Saalman, H. (1980). Filippo Brunelleschi. The Cupola of Santa Maria del Fiore. London, UK: A. Zwemmer Ltd.

Sanpaolesi, P. (1977). La Cupola di S. Maria del Fiore. Il progetto. La costruzione. Florence, Italy: Editrice EDAM.

Sgrilli, B. S. (1733). Descrizione e studi dell'insigne fabbrica di S. Maria del Fiore metropolitana fiorentina, Florence, Italy: Per Bernardo Paperini.

Tampone, G. (1996). Il restauro delle strutture di legno. Milan, Italy: Hoepli Editore.

Tommasi, C., Achille, C., \& Fassi, F. (2016). From point cloud to BIM: a modelling challenge in the cultural heritage field, International Archives of Photogrammetry, Remote Sensing and Spatial Information Sciences, XLI-B5, 429-436. https://doi.org/10.5194/isprs-archives-XLI-B5-429-2016 